\title{
Heritage Conservation and Sustainable Development in Sacred Places: Towards a New Approach
}

\author{
Sara Anas Serafi (serafi.sara@gmail.com) and Dr Kalliopi Fouseki (kalliopi.fouseki@ucl.ac.uk)
}

Keywords: sustainable development, spirituality, heritage conservation, Mecca, sacred

\section{Introduction}

The growing literature on heritage and sustainable development indicates a cultural turn which stresses the importance of culture and heritage as a driver for sustainable development (e.g. Albert 2015; Auclair and Fairclough 2015; Barthel-Bouchier, 2013; Landorf 2011; Rodwell 2007). This turn emerged as a reaction towards the omission of heritage and culture in development projects. Indeed, culture and heritage was (and still is to a great extent) somewhat hidden, and consequently neglected, under the umbrella of social sustainability.

The neglect of culture in sustainable development energised the proposition of a 'four-pillar' sustainable development model that comprises of economy, society, environment and culture (Hawkes 2001). The omission, and subsequent addition, of the cultural pillar reveals how reductive and misleading sustainable development models, in general, can be. Although, we acknowledge the significance of such models in visualizing complex interrelationships, we also contend that if such models are used blindly, and unconstructively, critical dimensions (such as that of culture) can be ignored. Sustainable development models need to be flexible, allowing the identification of as many pillars as necessary depending on each case study. For this to happen, understanding the significance and meanings assigned by stakeholders affected or associated with a development project is vital (Avrami et al. 2000)

We will illustrate our argument through the analysis of worshippers' responses towards the development projects around the historic and religious city of Mecca in Saudi Arabia. Our analysis will unveil the significance of the pillar of 'spirituality' within the context of heritage and sustainable development. This pillar, we argue, which lies at the interface of culture and society, should be the underlying foundation of sustainable development in Mecca.

Mecca is one of Islam's Holy cities and has been a destination for meditation and divine affirmation, dating back to pre-Islamic times around 2000 BCE (Dorduncu, 2006). For almost fourteen centuries now, Muslim's hearts have been yearning to visit this city, driven by a spiritual pull and the desire to fulfil pilgrimage duties. Millions of visitors find their way to Mecca annually to perform Hajj and Umra ${ }^{1}$, making the city a meeting point for people who come together from across the globe, pursuing the same divine purpose. In Mecca, it being both a sacred site and an inhabited living city, historic sites and remains can be categorized into three different types relating to the many phases of the city. While some sites are associated with religious or spiritual significance, relating to worship practices, the performance of Hajj or Prophet Mohammad's legacy, other sites can be viewed as more secular, merely associated with the city's history with no spiritual significance. The pressing urgency to expand

\footnotetext{
${ }^{1}$ Hajj refers to the annual pilgrimage to Mecca and Umra is another act of worship that takes place in the Holy mosque of Mecca.
} 
the city's Mosque to accommodate the increasing number of worshippers and visitors every year has encouraged rapid developments and expansion projects. Consequently, much of the Mosque's surrounding areas had to be demolished to make way for development, and with that many historic sites were also removed.

At the beginning of this research, and under the influence of informal discussions with professionals interested in the ongoing development works, the expectation was that pilgrims would oppose the development. This expectation was further reinforced by traditional attitudes of heritage professionals who are increasingly concerned about the effect of 'rapid modernization that attracted the desire for Western style modern patterns of development on Islamic built environment' (Kazimee 2012: xiii). After collecting 62 questionnaires answered by worshippers, we realised that development, in worshippers' views, can coexist with the spirituality and the heritage significance of the city as long as development functions as a vehicle for spirituality, facilitating the needs of worshippers.

\section{Methodology}

The key objective of this research was to carry out a preliminary study that will provide an insight into worshippers' spiritual and heritage experiences, and the impact (negative or positive) of the ongoing developments on this experience. In order to achieve the objective, three in-depth semi-structured interviews were carried out with local professionals in order to gain a better understanding of the place and the local reactions. This was followed by the design of a structured questionnaire aimed at investigating worshippers' attitudes and reactions towards development in Mecca.

The questionnaire comprised of three main sections including a section on worshippers' expectations, a section on their spiritual experience and a section specifically regarding conservation issues of historic remains and monuments on the site.

The ultimate goal of this study is to capture the general sense of what is happening on site, and to subsequently inform the design of a larger ethnographic study that is expected to start in September 2016. Due to the spiritual nature of the site, and also security and safety matters, the questionnaire at this stage had to consist of mainly close-ended questions. A few prompts accompanied some of the closed questionnaire statements in order to be able to qualify the information.

The interviewer (Sara Serafi) approached worshippers, through random sampling ${ }^{2}$, in the surrounding hotel lobbies and recruited local participants through personal networks. The questionnaire had to be short, respecting worshippers' time and space. The interviewer was accompanied by a relative for security reasons. The survey was conducted during the Holy month of Ramadan in summer 2015, the second busiest time of the year after Hajj, with over 3 million worshippers visiting. $55 \%$ of the respondents were female and $45 \%$ were male. $50 \%$ of the respondents were 30 years old or below and a further $50 \%$ were above 30 .

Participants in the survey came from various countries across the world including USA, Jamaica, Nigeria, Egypt, Indonesia, Pakistan and United Arab Emirate. No statistical differences between gender and age groups were noted in the responses. To facilitate the research and trace some statistical

\footnotetext{
${ }^{2}$ Sara was approaching every third worshipper entering the hotel lobby.
} 
differences, results were grouped into local and international respondents which, as presented below, allowed the identification of some differences between the two groups.

\section{Sustainable Development Challenges in the City of Mecca}

A vigorous campaign of development works took place in Mecca in 2008, under the title 'Makkah towards the first world'. It was initiated by Mecca's governor HRH Prince Khalid Al-Faisal (SyndiGate Media Inc, 2010). The campaign addressed the need for providing essential services to worshippers while preserving the city's identity. As stated by the Prince 'the project should be completed so that it can offer the highest level of services to worshippers'. The 'project should also preserve the indigenous and Islamic identity of the locations but in keeping with the modern image (Al-Sulami, 2011). Around 300 billion dollars was invested in the projects (Al-Saadi, 2014) with the aim of completion within a 10-year timeframe. The developments cover various services and facilities but mostly focus on accommodation and hospitality services. Probably one of the most known and controversial examples is the 'Makkah Clock Royal Tower' (Figure 1) which is part of the Abraj al Bait developments, a mega mixed-use development completed in 2012 that consists of a number of elite international hotels, a shopping mall, and prayer halls. Five times the size of London's Big Ben, the tower has become a landmark in Mecca and a 'beacon for some Muslim travellers' (The Middle East, 2011).

Figure 1: Makkah Clock Royal Tower (Photo: Anas Serafi 30/6/2015)

Other facilities include transport systems, banks and money exchange outlets, travel agencies, healthcare facilities, and general services like ablution facilities, toilets, and parking spaces. The scale of these development projects raise several questions in regards to how people perceive them, their effects on the spirituality of the place, and their relation to Mecca's image and identity. To make way for the new developments around 7000 real estate units had to be demolished (Abdul Ghafour, 2012), mountains were blasted and heritage sites were removed. Over the Mosque's expansion phases, priority was given to safeguarding sites related to worship practices. Other sites perceived as less religiously significant, such as sites associated with the city's secular history, were overlooked at the expense of the expansion (Serafi, 2015). While there have been recent efforts to conserve some of the remaining sites, it seems more attention is given to the conservation of tangible elements, and less to intangible aspects, such as the spirituality of the place. By spirituality, in the context of religious cultural heritage, we refer to the symbolic, cultural and emotional ways in which worshippers connect with a religious site. Cultural heritage in this context provides a means to convey and practise spiritual processes. As a result, other meanings associated with heritage in religious sites (such as historical or archaeological) are only of secondary importance for worshippers.

According to HRH Prince Khalid Al-Faisal, Mecca's governor, the first instruction received from the king regarding his role as governor was 'to put the welfare and progress of Mecca's residents and worshippers on top of my priority list' (McClatchy, 2015). Moreover, when initiating the 'Mecca towards the first world' campaign, he also stated that the campaign's four focal points are 'the human being, the place, the government sector, and the private sector' (The Independent, 2010). Furthermore, the Mecca and Holy Sites Development Authority's announced their aim to take into consideration urban, economic, residential, social, cultural, security, and environmental views throughout the development project (Al-Sulami, 2011). As it becomes evident from these statements, the spirituality of the place is omitted from the various dimensions associated with the development projects. 


\section{Heritage Conservation and Sustainable Development: A Critical Approach}

Despite its criticisms, the most widely known definition of sustainable development is that of the Brundtland Report, according to which 'sustainable development is development that meets the needs of the present without compromising the ability of future generations to meet their own needs' (WCED, 1987). This definition implies an intergenerational duty for present generations to sustain and transmit the planet and its resources to future generations. Accordingly, sustainable development is often visualized as a stool, or pediment, comprising of three (and more recently four) main dimensions including environment, economy, society and culture (Hawkes 2001; Pereira Roders and Van Oers, 2011, 2014, Van Oers and Pereira-Roders 2014). The World Commission on Culture and Development defined culture as 'ways of living together' and argued that this made culture a core element of sustainable development (UNESCO 1996). This emphasis re-orientates the focus of sustainable development theories and practices from people-nature relationships to people-to-people relationships. The underpinning argument is that without 'harmonious interactions between individuals and communities' the sustainability of the natural (and cultural) environment is not feasible (UNESCO 1996). The definition of culture here is strongly interlinked with social relations.

Hawkes (2001) distinguishes culture from the social pillar of sustainable development by arguing that culture focuses on the on-going negotiation of values that characterize human existence while the social pillar revolves around interactions of human organizations and communities. For Dessein et al. (2015) the interrelationship of culture with sustainable development is viewed as culture in, for and as sustainable development. 'Culture in sustainable development' describes culture's supporting role in larger processes of sustainable development and thus culture, in this sense, is one of four independent yet interactive contributors to sustainable development. 'Culture for sustainable development' attributes culture with the instrumental role of balancing all three pillars, guiding 'sustainable development between economic, social, and ecological pressures and needs' (Dessein et al. 2015, 28). Finally, 'culture as sustainable development refers to a worldview, a cultural system guided by intentions, motivations, ethical and moral choices, rooted in values that drive our individual and collective actions, and to a process and communication of transformation and cultural change.' (Dessein et al. 2015, 32).

The underpinning idea of all models (including the three and four pillar models) is that for development to be sustainable all pillars need to be balanced (Soini and Birkeland 2014). However, skepticisms have been expressed as to whether or not this balanced approach is pragmatic. Auclair, for instance, has noted that in urban sustainable development, the issues involved are complex, and the question remains if economic development, social cohesion and environmental quality can be simultaneously achieved $(2015,25-27)$. This has led researchers to prioritize certain pillars over others (see Cato 2009 for environmental priority; Throsby 2001 for economical and Kiddey and Schofield 2015 for societal). More recently, James, uses an approach that aims at sustaining a positive and vibrant social life by considering sustainability across an intersecting four-domain model: economics, ecology, politics, and culture (James, 2015).

While existing models can provide a useful visualization and mapping tool, if not used creatively, they can also be reductive and misleading, ignoring significant dimensions involved in a sustainable development project. Contributing to this ambiguity is the vagueness of the term 'sustainable (Pereira Roders \& Van Oers, 2011; James, 2015), which is often falsely used interchangeably with the term sustainability. The variety of models is indicative of the fact that there can be as many models and pillars as there is case studies. In view of this, we do not just propose an ideal model of sustainable development by simply adding a new pillar (that of spirituality) but mainly a process of thinking that is aligned with the particular needs of each place. In the case of sacred/heritage sites, we will examine the role of spirituality in sustainable development. In theory, this could fall under the wider 'social' 
and 'cultural' pillar. However, we want to stress the need for unpacking individual aspects of these wider dimensions (social and cultural) for certain sites.

\section{Spirituality in Sustainable Development}

A link between sustainability and spirituality has often been viewed as essential for fostering human relations and peoples' connection to nature (Kenworthy et al. 2006: 1449). According to Kenworthy et al. (2006: 1450) the very nature of sustainable development contains a spiritual question: where does the motivation to be sustainable lie? Spirituality here is linked with the moral duty to do 'the right thing' as, according to the authors, 'spiritual behaviour stresses human values such as humility, respect, compassion and responsibility' (ibid: 1550). Accordingly, spirituality in the context of sustainable development provides a forum for addressing critical issues such as social justice, personal and collective human rights and personal values (ibid: 1551).

In economic-oriented development studies there is a growing emphasis on understanding local peoples' spirituality in sustainable development practices (e.g. Ver Beek 2002; Verhelst and Tynandele 2002) and integrating spirituality as an additional pillar in sustainable development models (Krempl 2014; Ulluwishewa 2014). Indeed, the importance of spirituality from the viewpoint of changing ourselves has been acknowledged by authors as a contributing factor to sustainable development (e.g. Ikerd 2005; Reid 1995).

In its literal meaning, spirituality refers to the state of being with spirit (Ulluwishewa 2014: 5). Ulluwishewa (2014) has argued that spiritual growth and economic growth are mutually beneficial. His approach is driven by the idea that the world would be a better place if spirituality principles, that advocate equity and fairness, were integrated into conventional development studies which purely focus on economic growth. Although this may sound idealistic, our research in Mecca also concludes that economic growth and spiritual processes can co-exist as long as economic-driven developments respect and facilitate the worshippers' needs.

Similarly, Krempl (2014) argues from an environmental perspective that any model of sustainable development is incomplete without a spirituality pillar. Spirituality in Krempl's research is identified with hope, ethical values and meaning - all of which could be located under social sustainability. However, by unfolding these elements, reassurance can be provided that they will not be left out.

An interesting conceptual paper produced by the religious community of Bahá'í in 1998, as part of the World Faiths and Development Dialogue, also affirms the central role of spirituality in sustainable development (Bahá'í International Community, 1998 http://iefworld.org/bicvsid.htm). This concept paper focuses on the importance of creating measures to assess development progress through the perspective of spiritual principles. The paper begins by outlining a Bahá'í perspective on development. It then introduces the concept of spiritually based indicators for development. The Bahá'í community defines 'meaningful development' as development requiring that the 'seemingly antithetical processes of individual progress and social advancement, of globalization and decentralization, and of promoting universal standards and fostering cultural diversity, be harmonized'. They stress the importance of 'material progresses' in serving as 'a vehicle for spiritual and cultural advancement'. Spirituality is viewed as a thread, a foundation rather than as a distinct pillar of sustainable development. Similarly, in the case of Mecca, we will argue that spirituality should constitute the underpinning foundation of sustainable development projects in the city.

Despite increasing acknowledgment of the role of spirituality in sustainable development, as indicated above in the case of Mecca and stressed in literature (e.g. Lunn 2009), development still largely focuses 'on exterior aspects of human society that relate to material needs, and has tended to exclude 
the more qualitative interior components of human life, such as ethical, cultural, psychological and spiritual needs' (Hochachka 2005: 111). However, interiority (emphasis on development of these interior aspects) is critical for sustainable development (ibid: 110) because, ultimately, 'it is in the process of self-determination that communities will find emancipation from current conventional development models and engage with development which is appropriate and sustainable' (Lunn 2009:957).

\section{Heritage Conservation and Sustainable Development in Mecca: Worshippers' Responses}

This section will summarize worshippers' attitudes towards the impact of the development projects on heritage and the spiritual nature of the place. 62 respondents answered the questionnaire comprising of 37 and 25 international and local worshippers respectively, the majority of whom (92\%) had visited Mecca before.

Although the sample size does not allow a conclusion of statistically significant results, the findings are of great interest in highlighting areas for further research as well as emphasising the necessity to consider 'spirituality' as an essential aspect of sustainable development, especially in sacred sites.

One of the first questions aimed to examine the extent to which participants believed that Mecca had changed over time. Not surprisingly, those who had visited Mecca before thought that Mecca had changed significantly (Figure 2).

Figure 2: Prior visit to Mecca cross-tabulated with perceptions of 'image' of Mecca and the degree of change

Respondents commented, for instance, on how the city 'is losing its holy spirit with all the [surrounding] cranes and buildings' and how the surrounding landscape is becoming 'more commercial' and 'industrious'.

Attitudes towards the idea of 'development' were, however, positive when they related to the provision of additional accommodation services (Figure 3); expressing sentiments of awe saying "we were surprised by how accommodating it was!" and commenting that the developments were "great and made more room for pilgrims".

\section{Figure 3: Worshippers' responses towards developmental services}

Despite the positive reactions regarding the provision of accommodation services, when asked to scale their general impressions towards the overall development programming, overall attitudes were negative; 4 out of 10 of the respondents viewed the development projects as very negative or negative (Figure 4). 


\section{Figure 4: Worshippers' overall attitudes towards development works}

Those respondents who viewed the development works as negative were prompted to choose among a list of factors that contributed to this negative perception. Those factors included height/scale, building functions, architectural style/look, accessibility/congestion, and globalization of brands.

The majority of the respondents (54\%) considered height and scale as the most negative aspect of the development projects, while $34 \%$ cited lack of accessibility and congestion, regardless of whether they were local or international (Figure 5). No statistically significant variation was noted between the different profiles of respondents. Similarly, one of the professionals interviewed touched upon the problem of scale, mentioning that "in the past a lot of the buildings were adjacent to the mosque and didn't cause any issues, what has changed is the scale factor".

\section{Figure 5: Elements of development works that were viewed less favourably by respondents}

The respondents who viewed the development projects positively were also asked to choose from a list of positive factors contributing to their perception. The list included convenience, international living standards, landmarks that represent power status, and modernization. 23 of the respondents appreciated the convenience that this development provides to the visitors, 3 liked the feeling of modernization projected by the works and 1 appreciated the international living standards. However, the local respondents clearly tended to adopt an overall negative attitude towards the development projects (76\%) (Figure 6).

Figure 6: Attitudes of local and international worshippers towards the development works taking place around the Mosque.

Mecca's historic sites can be divided into three categories 1. Related to worship practices e.g. Arafat, Mina, etc... 2. Related to the Prophet's legacy e.g. Ghar Hira, Ghar Thawr, etc... 3. Related to the city's history e.g. Souk Al-Moda'a, Al-Haramain Museum, etc... Given the existence of historic remains on site (around the Mosque), respondents were also asked to choose, from a provided list of historic sites, which ones that they were most familiar with (Figure 7). 
Figure 7: Familiarity with types of historic sites as categorized.

The figure above shows that sites related to the city's history were less known by the respondents, although locals tended to be more familiar with this type of heritage than international worshippers. One of the interesting finds was that the material culture related to the city's history is of less interest or urgency for conservation in contrast to the material culture related to the spiritual nature of the site. In this regard, no variations were observed between the local and international worshippers. Moreover, for the City's historical remains, respondents did not oppose the idea of creating a museum, while this was not viewed favourably for the first two types of remains (Figure 8).

Figure 8: Worshippers' responses towards the development of a museum for different types of heritage

The above findings indicate a clear priority for the spirituality of the place which overshadows the heritage and historic significance of the site. To this end, a museum is favourable for the city's history but not for the city's religious character. In addition, development (especially linked with the provision of accommodation services) is desirable, but overall -there is a strong reaction against high scale buildings that disrupt the spiritual nature of the landscape, especially from locals.

\section{Integrating Spirituality into the Sustainable Development of Sacred-Heritage Places}

This section advocates the integration of the 'spiritual' dimension into traditional models of sustainable development as the underlying thread, especially for places of sacred and heritage significance (Figure 9). We argue that each place is unique and thus an in-depth investigation through consultation with involved stakeholders and communities is required in order to identify the distinctive, underlying value of individual places. For the case of sacred sites, such as Mecca, it becomes apparent that cultural heritage elements and economic drivers are viewed as less important by worshippers while spirituality is the underpinning thread of all 'pillars' of sustainable development.

Figure 9: Visualizing Sustainable Development with Spirituality as the Underpinning Thread in the city of Mecca. Spirituality is not depicted as an additional, distinct pillar but as the underpinning thread of all pillars.

Our analysis further showed that modern development is viewed favourably by the worshippers as long as it is intended to facilitate the sacred purpose of the place. It was clearly revealed that the essence of Mecca's identity is its spirituality - this is what keeps it alive and attracts the millions of visitors year round. Metaphorically speaking, if the city of Makkah can be looked at as a body then the spiritual aspect could be described as its soul. Consequently, the risk of gradually losing that aspect could in fact lead to the metaphorical death of the city. This observation emphasises that, when speaking of conservation in Mecca, conserving the spirituality of a place is of paramount importance and should possibly be the main priority in decision making.

Most worshippers agreed that developments surrounding the Mosque do indeed affect their spiritual experience. The key disruptive factors proved to be the height and scale of the surrounding buildings. This observation is further verified by an architectural study which indicated that meaningful and 
intense spiritual experiences can be evoked in a place if the three inter-related areas of sustainability are combined with humanity and sensuality in the design (Birch and Sinclair 2013). A similar point was stressed in the professionals' interviews, suggesting that to protect that sense of spirituality when undertaking developments, the Ka'aba (the Holy Mosque's center) should be taken as the scale reference point in planning.

One of the main observations from the survey findings was the clear distinction between local and global perspectives on the developments. While the locals generally viewed the developments as negative, the international respondents found them positive overall. The evident opposing views prompt further exploration on issues that relate to attachment and sense of belonging to a place. The fact that international visitors only visit Mecca for a limited time period, to perform certain worship practices, gives them a temporary perspective. This thought was further supported in the survey responses, where almost all the international respondents prioritized convenience as the top reason for viewing the developments as positive. Shackley (2001) has reiterated this idea by claiming that tourist type visitors, or people visiting from abroad, are usually more open to changes in a certain historic or sacred site because they lack the same strong sense of attachment to the place as locals or residents. On the contrary, the locals' perspectives are driven by a stronger sense of attachment and belonging to their city, rendering them more sensitive to any changes that may be viewed as intrusive to their permanent surroundings. Another explanation for the local's negative view towards the developments may be linked to their knowledge of the real economic motives behind those developments. The locals view them as an emblem of economic capitalization, while international visitors, who are not directly affected by that issue, are not as bothered by it.

These findings further illustrate the importance of integrating local voices into the decision making process and the sensitivity with which those voices should be handled. This issue was also discussed in Dr. Angawi's interview (2015), expressing that "we must not only consider the international visitors' needs when planning developments, but also Makkah's local residents". Achieving a balance between accommodating both needs, in his opinion, would help attain successful developments. Sardar (2014) has rightly advocated for local voices to be considered in the process since Mecca, other than being a Holy and religious symbol, is also a city where people live out normal lives. Therefore decisions affecting Mecca also affects their daily lives.

\section{Conclusion}

In this chapter we argued that reductive models of sustainable development can be misleading if they are not used in a constructive, creative and critical manner because there is a high possibility that important aspects related to the meanings and values of a heritage place are ignored. This argument was illustrated through the case of Mecca, a historic and sacred city which is under the threat of rapid development projects. The initial hypothesis that stimulated this piece of research was that development and heritage conservation cannot co-exist. However, our study in Mecca showed clearly that development and heritage conservation can co-exist if development acts as a vehicle for enhancing spirituality through addressing directly the needs of worshippers. Moreover, our analysis unveiled the tension between religion and heritage. For worshippers, the religious significance of the city is apparently more important. Museumfication of the remains is only desirable in the historic parts of the city that do not directly link to its religious significance. This was further supported by statements from key developers, admitting that sites related to worship or connected to the Prophet's legacy are given priority over non-religious sites within the planning process.

Another interesting observation - although not statistically significant due to the small sample - is the variation of responses between local and international worshippers. For worshippers spirituality of the place is delineated within the geographical boundaries of the site and its immediate surroundings. 
For the locals the spirituality of the place transcends these narrow boundaries and expands to the wider city. This can explain why locals tend to be more negative towards the development projects.

This analysis, we hope, has opened new avenues for future research while informing future sustainable development practices. We would like to advocate for an approach to sustainable development that assesses and identifies all possible aspects and dimensions linked with a place. We view the pillars of sustainable development models as projections of these values. In the case of Mecca we did not fully capture the views of all involved stakeholders. It is expected that such views will clash, specifically some religious views, resulting in power struggles between the different stakeholders that are associated with sites of such a sacred nature. In Mecca's case, for instance, a noticeable challenge was the resistance coming from religious extremist views, there is a fear that giving certain monuments or sites extra significance could make them prone to 'wrongful' worship practices leading people to seek blessings from those monuments or even cultivating idol worshipping, both of which are against Islamic principles. The dissonant nature of values raises further questions. How can sustainable development be achieved when the dimensions, pillars or values are in conflict? Which pillars should be prioritised and which ones should function as the underlying foundation of sustainable development? These are critical questions that need to be addressed in future relevant studies.

\section{References}

Abdul Ghafour, P.K., 2012. Balanced development new strategic goal, says Makkah governor. Tribune Business News. Tribune Content Agency LLC: Washington.

Albert, M.T. ed., 2015. Perceptions of Sustainability in Heritage Studies (Vol. 4). Walter de Gruyter $\mathrm{GmbH} \&$ Co KG.

Al-Saadi, K., 2014. Development projects in Makkah to cost SR300bn. Tribune Business News. Tribune Content Agency LLC: Washington.

Al-Sulami, Md., 2011. Makkah project aims at 'balanced development'. Tribune Business News. Tribune Content Agency LLC: Washington

Angawi, S., 2015. Interview by Sara Serafi, voice recording, 4 May 2015

Auclair, E. and Fairclough, G. 2015. Eds. Theory and Practice in Heritage and Sustainability: Between Past and Future. London: Routledge.

Avrami, E.C., Mason, R. and De la Torre, M., 2000. Values and heritage conservation: research report. Los Angeles: Getty Conservation Institute.

Bahá'í International Community, 1998. Valuing Spirituality in Sustainable Development.

Birch, R. and Sinclair, B R., 2013. 'Spirituality in Place: Building Connections Between Architecture, Design, and Spiritual Experience', Architectural Research Centers Consortium, 80-87. 
Dorduncu, M., 2006. The Yildiz Albums of Sultan Abdulhamid II Mecca-Medina. New Jersey: The Light, Inc.

Initial Considerations Regarding the Creation of Spiritually Based Indicators for Development Lambeth Palace, London, 18-19 February 1998 Available online:

https://www.bic.org/statements/valuing-spirituality-development

Barthel-Bouchier, D., 2012. Cultural heritage and the challenge of sustainability. Left Coast Press.

Birch, R. and Sinclair, B.R., 2013, July. Spirituality in Place: Building Connections Between Architecture, Design, and Spiritual Experience. In ARCC Conference Repository. The Visibility of Research: Culture, New Ideas, Minor Voices, and Topics of the Margins. 80-87.

Cato, M.S., 2009. Green economics: an introduction to theory, policy and practice. Earthscan.

Dessein, J., Soini, K., Fairclough, G. and Horlings, L. eds. Culture in, for and as sustainable development. Conclusions from the Cost Action IS1007 Investigating Cultural Sustainability. Finland: University of Jyväskylä. http://www.culturalsustainability.eu/conclusions.pdf

Hawkes, J. 2001. The fourth pillar of sustainability: culture's essential role in public planning. Common Ground.

Hochachka, G. 2005. Integrating interiority in community development. World Futures 61 (1-2), 110126.

Ikerd, J.E., 2005. Sustainable capitalism: A matter of common sense. Columbia, SC, USA: Kumarian Press.

Kenworthy, J., Marinova, D. and Narayanan, Y., 2006. In a city like Delhi: Urban spirituality, sustainability and women. Portal: journal of multidisciplinary international studies, 3(1), pp.1-22.

Kazimee, B.A., 2012. Heritage and sustainability in the Islamic built environment. Wit Press.

Kiddey, R. and Schofield, J. 2015. Keeping it real: social sustainability in the homeless heritage project in Bristol and York. In Auclair, E. and Fairclough, G. (eds). Theory and Practice in Heritage and Sustainability. London: Routledge, 40-53.

Krempl, S. 2014. Is spirituality the essence of spirituality?, in Lunn, J. and Bizjak, S. (eds), The truth is out there, Western Australia: Black Swan Press, 169-181.

Landorf, C., 2011. Evaluating social sustainability in historic urban environments. International Journal of Heritage Studies, 17(5), pp.463-477. 
McClatchy, 2015. Makkah development 'top priority'. Tribune Business News. 22 May 2015.

Pereira Roders, A. and van Oers, R., 2011. Editorial: bridging cultural heritage and sustainable development. Journal of Cultural Heritage Management and Sustainable Development, 1(1), pp.514.

Pereira Roders, A. and Van Oers, R., 2014. Wedding cultural heritage and sustainable development: three years after. Journal of Cultural Heritage Management and Sustainable Development, 4(1), pp.2-15.

Reid, D., 2013. Sustainable development: an introductory guide. London: Routledge.

Rodwell, D., 2008. Conservation and sustainability in historic cities. John Wiley \& Sons.

Sardar, Z., 2014. Mecca: The Sacred City. New York: Bloomsbury.

Serafi, A., 2015. Interview by Sara Serafi, written notes, 3 July 2015.

Shackley, M., 2001. Managing Sacred Sites. s.I.:Continuum.

Soini, K. and Birkeland, I., 2014. Exploring the scientific discourse on cultural sustainability. Geoforum, 51, pp.213-223.

SyndiGate Media Inc , 2010. Governor pledges more development in Makkah. Arabianbusiness.com. December 92010.

The Independent, 2010. Saudi Arabia; Experience Makkah. United Kingdom: World Report International Ltd.

The Middle East, 2011. High-class hospitality comes to Makkah. December 2011, p.53.

Ulluwishewa, R., 2014. Spirituality and Sustainable Development. Basingstone: Palgrave Macmillan.

UNESCO 1996. Our creative diversity. Paris: World Commission on Culture and Development.

Van Oers, R. and Pereira Roders, A., 2014. Aligning agendas for sustainable development in the post 2015 world. Journal of Cultural Heritage Management and Sustainable Development, 4(2), pp.122132.

Ver Beek, K.A., 2000. Spirituality: a development taboo. Development in practice, 10(1), pp.31-43.

Verhelst, T., Tyndale, W., Verhelst, T. and Tyndale, W., 2002. 1. Cultures, spirituality, and development. In D. Eade ed.,, Development and culture (pp. 1-24). Oxfam Publishing. 
WCED (World Commision on Environment and Development) 1987. Our Common Future. http://www.un-documents.net/wced-ocf.htm

\section{Biographical notes}

Sara Serafi holds a BSc (Hons) in Architecture from Effat University, Jeddah, Saudi Arabia and an MSc in Sustainable Heritage from University College London. Since September 2016 she has been working with Atkins' London office.

Dr Kalliopi Fouseki is a Lecturer at the Institute for Sustainable Heritage at the University College London where she coordinates the MSc in Sustainable Heritage. Prior to this, she worked in several museums in the UK and abroad. She holds a BA in Archaeology and History of Art from the University of Athens, a MA in Cultural Heritage Studies and a PhD in Heritage Management, both awarded from the University College London. 